\section{Cahiers de littérature orale}

$71 \mid 2012$

Interlocutions périlleuses

\title{
Lydia GABORIT, 2012, Littératures orales et populaires de l'île de Noirmoutier
}

\section{Cécile Leguy}

\section{OpenEdition}

Journals

Édition électronique

URL : https://journals.openedition.org/clo/1520

DOI : $10.4000 /$ clo. 1520

ISSN : 2266-1816

Éditeur

INALCO

\section{Édition imprimée}

Date de publication : 1 janvier 2012

Pagination : 191-194

ISBN : 978-2-85831-206-1

ISSN : 0396-891X

\section{Référence électronique}

Cécile Leguy, "Lydia GABORIT, 2012, Littératures orales et populaires de l'île de Noirmoutier ", Cahiers de littérature orale [En ligne], 71 | 2012, mis en ligne le 28 avril 2014, consulté le 30 juin 2021. URL : http:// journals.openedition.org/clo/1520; DOI : https://doi.org/10.4000/clo.1520

Ce document a été généré automatiquement le 30 juin 2021.

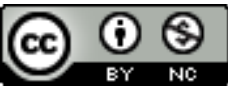

Cahiers de littérature orale est mis à disposition selon les termes de la Licence Creative Commons Attribution - Pas d'Utilisation Commerciale 4.0 International. 


\title{
Lydia GABORIT, 2012, Littératures orales et populaires de l'île de Noirmoutier
}

\author{
Cécile Leguy
}

\section{RÉFÉRENCE}

Lydia GABORIT, 2012, Littératures orales et populaires de l'île de Noirmoutier, Paris, L'Harmattan, coll. « Patrimoine culturel immatériel », 477 p. + CD. ISNB

978-2-296-99357-0.

1 Peut-on collecter de la littérature orale à la fin $\mathrm{du} \mathrm{xx}^{\mathrm{e}}$ siècle, dans une région de la côte Atlantique régulièrement envahie par des vacanciers venus d'ailleurs ? Quelles sont les occasions où l'on peut encore entendre dire des légendes, des contes, des monologues de marins quand les télévisions trônent dans les maisons? « La parole, porteuse des traditions, celle du conte merveilleux, des légendes et des proverbes, qui demeure audible dans l'île de Noirmoutier est une parole âgée, fragile et respectable, qui disparaît avec ses derniers détenteurs. La civilisation îlienne est en perte d'oralité spécifique », nous dit Lydia Gaborit (p.15), partageant son impression d'arriver trop tard, de ne trouver plus que des « miettes »... « J'ai travaillé sur un matériau éparpillé, en éclat, mutilé. J'ai travaillé aussi sur l'absence de ce matériau, sur sa transparente peau de chagrin qui semblait s'amoindrir encore au fur et à mesure que je désirais l'approcher, le sauver de l'oubli. J'ai eu souvent ce sentiment, peut-être vain, de sauver cette parole populaire qui n'était plus ni belle ni pleine de sens, mais semblait balbutier maladroitement » (p. 151).

2 Lydia Gaborit a su cependant gagner la confiance de quelques personnes, noter leurs paroles, enregistrer leurs voix, rassembler quelques contes merveilleux, des prières et des histoires religieuses, des contes de mensonges, facéties et histoires drôles, des légendes et des récits de sorcellerie, des comptines, des proverbes, des chansons et 
quelques monologues de marins. Grâce au CD joint au livre, il est possible d'entendre quelques-uns de ces textes et surtout des chansons, genre demeuré le plus vivant. Cette édition complète et bienvenue de sa thèse nous introduit ainsi au cœur d'une société particulière, familière et mystérieuse en même temps. Au début des années 1980, période de la collecte, l'île s'est en effet considérablement rapprochée du continent suite à la construction d'un pont et d'une quatre-voies qui amènent chaque été leurs flots de touristes. Cette virgule de terre n'a pourtant jamais été isolée, une chaussée submersible - le Gois - balisée au XvIII ${ }^{e}$ siècle et pavée depuis les années 1930, la reliant à chaque marée basse au continent. L'histoire a cependant donné à cet avant-poste du territoire français une coloration particulière, comme le rappelle l'auteur au début de son ouvrage. De la présence légendaire d'une société matrilinéaire de «femmes rousses » aux mœurs païennes à l'établissement d'une vie insulaire christianisée dont les hommes, souvent pêcheurs ou marins, sont très absents, l'île a connu des présences masculines marquantes : occupation romaine, invasions barbares, établissement d'un monastère et évangélisation par saint Philibert et ses moines aux habits noirs qui lui donnent son nom, puis raids des Normands qui en font leur point de ralliement au $\mathrm{IX}^{\mathrm{e}}$ siècle. L'histoire de Noirmoutier concentre celle du pays quand, à partir du XIV $v^{e}$ siècle, la résistance contre l'invasion anglaise et le rôle d'avant-garde joué par leur île permet aux Noirmoutrins d'obtenir quelques privilèges royaux, qui ne les épargnent ni des attaques de pirates, ni des guerres de religion, ni de la descente des Hollandais. Les guerres de Vendée déchirent l'île en deux, la scission entre Républicains et Royalistes se faisant encore ressentir de nos jours. Pendant la Seconde Guerre mondiale, Noirmoutier retrouve son rôle d'avant-poste et voit la construction de plusieurs blockhaus censés contrer le débarquement allié.

3 Lydia Gaborit a mené son étude dans deux villages du sud de l'île, Barbâtre et l'Épine, le premier vivant surtout du tourisme tandis que le second, village de sauniers et de pêcheurs plus isolé et plus pauvre, a gardé une certaine authenticité. Les quatorze individus rencontrés n'étaient ni de simples conteurs ni de simples informateurs. Certains parmi eux avaient un talent reconnu, tels Roublotte, saunier de l'Épine, dont le répertoire de "contes de mensonges" était particulièrement apprécié et Bitard le marin, plus jeune et polyvalent, narrant contes et légendes, mais aussi récits facétieux et longs monologues de marins qui faisaient sa réputation. Lydia Gaborit s'est également adressée à des érudits locaux qui sans être conteurs à proprement parler, maitrisaient un savoir local qui les passionnait. Elle s'est aussi mise à l'écoute de quelques conteuses familiales, tantes et mère racontant dans l'intimité des histoires de leur vie mêlées à celles de la vie des autres.

Cette recherche sur les traditions orales de son île natale a conduit Lydia Gaborit à une réflexion plus générale sur les conditions et possibilités de ce type d'enquête aujourd'hui, sur les méthodes et leurs biais, sur la parole populaire et la place qu'elle peut encore avoir dans une société comme la nôtre. Comme elle l'a relaté elle-même dans un précédent numéro des $\mathrm{CLO}^{1}$, elle l'a également conduite à une ethnologie du proche, de l'intime où le chercheur lui-même se découvre en faisant resurgir histoires et chansons oubliées de la bouche des anciens. Cette collecte, en elle-même intéressante de par ses particularités locales en relation avec l'histoire et la vie noirmoutrines, est ainsi également source de débat et de questionnement pour toute personne s'intéressant à la littérature orale. En comparant par exemple deux versions de la «Dame Blanche» racontées par une même personne, se sachant enregistrée la 
deuxième fois et non la première, on constate combien le poids de la situation peut jouer sur la production orale elle-même. La conteuse ne produit plus la même parole, elle semble contrôler ses expressions, elle parle en français, s'autocensure et produit de nombreux phatiques ("tu comprends?", «tu sais bien »... ) tandis que la première version, racontée en s'affairant à la cuisine au cours d'un bavardage, en patois, est d'un rythme plus enjoué et affirmé, incluant un épisode local relatant le déguisement d'un homme de Noirmoutier en Dame blanche (p. 162 sqq). Cependant, la première version a été "volée " tandis que la deuxième est recueillie dans des conditions d'enquête honnête, et c'est cette deuxième version que la conteuse a produite pour la collecte, pour qu'elle soit enregistrée et conservée. Par ailleurs, Lydia Gaborit n'hésite pas à retenir dans son corpus des versions hésitantes ou mêlées, où l'on perçoit combien le conteur peine à retrouver le fil d'un récit qu'il n'a sans doute pas eu l'occasion de dire depuis des années, par exemple ce conte de "Culotte verte» raconté par un octogénaire en présence de sa femme, elle aussi conteuse, qui intervient régulièrement pour corriger ou préciser sa parole.

5 Ce sont surtout les contes de mensonges qui retiennent l'attention de l'auteur dans la mesure où ils sont encore pratiqués, notamment dans cette "commune libre de Gabion », petit univers autonome géré par quelques "menteurs" de l'Épine. Les conteurs-menteurs sont des improvisateurs malicieux, qui se retrouvent au café du Port ou sur un banc face à la mer pour discuter. Le conte de mensonge est éphémère et prend tout son intérêt dans l'événement de la situation, même si l'on peut se souvenir et reprendre des "menteries" devenues célèbres. En ce sens, il résiste à la patrimonialisation, même si la pratique se situe dans la continuité des sotties du Moyen Âge. « Il me semble que le conte de mensonge constitue par sa réalité et sa vivacité une réaction à la disparition des autres récits d'oralité traditionnelle, qu'il revendique bien et sans fausse honte, son caractère de duperie volontaire. C'est lui qui se moque à son tour de cette culture officielle qui a su si bien cloisonner et étouffer le conte merveilleux et le déposséder de ses fonctions » (p. 206).

6 La deuxième partie de l'ouvrage rassemble les textes de la collecte, avec pour chacun la date de l'enregistrement et les précisions sur l'identité et l'âge du performeur. Les chansons sont accompagnées de leur partition musicale. Les récits sont transcrits en tenant compte des circonstances de la performance, des interventions des auditeurs, des différentes intonations, etc. L'ensemble des textes est suivi d'un glossaire inédit des termes propres au dialecte noirmoutrin. Quelques reproductions de cartes postales anciennes viennent agréablement clore cette somme vivante et passionnante d'une littérature orale populaire à laquelle nous pouvons ainsi encore être introduits pour, peut-être, mieux comprendre les rêves et les peurs des îliens d'aujourd'hui.

\section{NOTES}

1. Lydia Gaborit, « L'imparfait dans la quête », Cahiers de littérature orale, $n^{\circ} 63-64$ (2008, 161-169). 